\title{
Genetic characterization of St. Louis encephalitis virus isolated from human in São Paulo, Brazil
}

\section{Cecília Luiza Simões dos Santos/ ${ }^{+}$, Maria Anice Mureb Sallum* , Heitor Moreira Franco, Fabíola Maiumi O shiro, Iray Maria Rocco}

\author{
Serviço de Virologia, Instituto Adolfo Lutz, Av. Dr. Arnaldo 355, 01246-902 São Paulo, SP, Brasil * Departamento de \\ Epidemiologia, Faculdade de Saúde Pública, Universidade de São Paulo, São Paulo, SP, Brasil
}

The molecular characterization of SPH253157, a new strain of St. Louis encephalitis virus (SLEV), isolated in 2004 from the first case of human infection recognized in the state of São Paulo, Brazil, is reported. The patient, presenting a febrile illness without neurological involvement, was hospitalized as a probable case of dengue fever. Genomic RNA was isolated from the supernatant of C6/36 cells infected with acute phase-serum specimen of the patient and the envelope gene was amplified by reverse-transcription-polymerase chain reaction. The complete nucleotide sequence of the envelope gene of this isolate was directly sequenced from the amplified products and compared with other Brazilian and American SLEV strains. Phylogenetic analyses were carried out under maximum likelihood criterion with outgroups both included and excluded. Outgroups comprised four flavivirus of the Japanese encephalitis group. Phylogeny also included Bayesian analysis. The results indicated that the new SLEV isolate belongs to lineage III, being closely related to an Argentinean strain recovered from Culex sp. in 1979. It is concluded that there are at least 3 lineages of SLEV in Brazil.

Key words: St. Louis encephalitis virus - envelope gene sequence - phylogeny - Brazil

St Louis encephalitis virus (SLEV) belongs to the family Flaviviridae, genus Flavivirus, within the Japanese encephalitis virus group (Calisher et al. 1989). The genome of flaviviruses contains a single-stranded positive sense RNA, about 10,800 nucleotides long that encodes 10 distinct proteins in a single reading frame (Chambers et al. 1990). SLEV is the etiologic agent of St. Louis encephalitis, a disease of epidemiological importance in North America. This virus was first isolated in the United States of America (US) in 1933, during an outbreak, which occurred in St. Louis and Kansas City, Mo. (Muckenfuss et al. 1934). In the US intermittent and unpredictable epidemics have been occurring during the last decades. The majority of SLEV infections is sub clinical or result in mild illness. The severity of infections is strongly dependent on the age of a patient, and the case fatality rate during epidemics ranges from $2 \%$ in young adults to more than $22 \%$ in the elders (Monath \& Heinz 1996). In spite of being endemic in Central and South America, causing sporadic illness, occurrence of SLEV outbreaks is unknown (Spence 1980, Monath \& Heinz 1996).

The biological cycle of SLEV in nature involves primarily wild birds and several mosquito species; humans and other mammals are considered to be incidental hosts (Monath \& Heinz 1996). In the US, Culicinae mosquitoes and birds, Passeriformes and Columbiformes, are involved in the dynamics of SLEV transmission. The transmission

Financial support: Fapesp (no. 2004/07819-6) and CNPq (no. 305339/2003-6); to CLSS; to MAMS CNPq (501529/2003-9)

+Corresponding author: simoes.santos@uol.com.br

Received 29 August 2005

Accepted 21 December 2005 cycle varies regionally, depending on the biology of mosquito species, virulence of SLEV strains and susceptibility to infection of vertebrate hosts (Monath \& Tsai 1987, Day 2001, Reisen 2003). In Central and South America SLEV transmission cycle is not well defined, but it may include mosquito species of the genera Culex, Mansonia, Haemagogus, and Sabethes. A variety of bird taxa, including herons, egrets, and cormorant may be virus reservoirs (Spence 1980, Monath \& Heinz 1996, Reisen 2003).

The occurrence of SLEV in Brazil was recorded in 1953, by the finding of antibodies to this virus in residents of the Amazon Valley (Causey \& Theiller 1958). A pool of mosquito Sabethes belisarioi, captured along the BelémBrasília highway, was the source for the first isolation of a SLEV strain (Causey et al. 1964). Later in 1970 and 1978 two strains were recovered from human blood in Amazon region. In both cases the patients developed a febrile illness with jaundice, neither of them presenting neurological involvement (Pinheiro et al. 1981, Vasconcelos et al. 1998). SLEV was also found in the Southeast region of Brazil where it was isolated from wild birds, rodents, and sentinel mice during a surveillance program on arbovirus activity carried out in the state of São Paulo from 1967 to 1969 (Lopes et al. 1979).

In the summer of 2004, after more than two decades of the last human Brazilian report, a clinical case of infection by SLEV was detected in the state of São Paulo. Epidemiologic data about the SLEV case was fully detailed by Rocco et al. (2005). Briefly, a patient, suffering from severe uncharacterized febrile illness without neurological involvement, was hospitalized as a probable case of dengue fever. Serological tests detected antibodies to flavivirus but were negative in tests specific for Dengue virus (DENV). The virus was isolated in cells culture inoculated with patient acute phase serum and identified by reverse-transcription-polymerase chain reaction (RT- 
PCR) and sequencing (Rocco et al. 2005). SPH 253157 is the first strain of SLEV isolated from human reported in the state of São Paulo and the third one in Brazil.

In Brazil, the genetic diversity of SLEV has been poorly explored and only a few strains have been characterized at molecular level. In the present study, we determined the entire nucleotide sequences of the Envelope (E) gene of SPH 253157 strain. In addition, representative E sequences of SLEV lineages as well as previously published E sequences of Brazilian SLEV were downloaded from GenBank (Kramer \& Chandler 2001) and included in the study for comparison with SPH 253157 strain. The main objectives of this study are: (1) to estimate genetic relationships among SPH 253157 and several previously collected Brazilian strains and other SLEV American isolates; (2) to characterize genetic lineage of SPH 253157 isolated from a human patient infected in the state of São Paulo.

\section{MATERIALS AND METHODS}

Viruses - The SLEV SPH 253157 strain was isolated from acute phase-serum specimen of a patient in monolayer cultures of clone C6/36 cells of Aedes albopictus (Rocco et al. 2005). Viral strains, locations, years of isolation, and GenBank accession numbers of the $\mathrm{E}$ sequences utilized in the phylogenetic analyses are listed in Table I. Sequences from Japanese encephalitis virus (JEV) (Accession \# M55506 (Nitayaphan et al. 1990); West Nile virus (WNV) Accession \# M12294 (Castle et al. 1985); Kunjin virus (KUNV) Accession \# D000246 (Coia et al. 1988), and Murray Valley encephalitis virus (MVEV), Accession \# X03467 (Dalgarno et al. 1986) were used as outgroups in the phylogenetic analysis.

RT-PCR and nucleotide sequencing - Viral RNA was isolated from first passage cell culture supernatant using the QIAmp Viral RNA Extraction Kit (QIAGEN, Valencia,

TABLE I

St. Louis encephalitis virus strains included in phylogenetic analysis of envelope gene

\begin{tabular}{|c|c|c|c|c|}
\hline Strain & Location & Year & Host & GenBank Acc. no. \\
\hline TexU1193 & Texas, US & Unknown & Unknown & AF205510 \\
\hline $98 \mathrm{~V}-3181$ & Texas, US & 1998 & Culex quinquefasciatus & AF205500 \\
\hline PV7-3389 & Texas, US & 1987 & Culex quinquefasciatus & AF205491 \\
\hline $83 \mathrm{~V}-4953$ & Texas, US & 1983 & Culex quinquefasciatus & AF205498 \\
\hline Texas 1955 & Texas, US & 1955 & Human & AF205512 \\
\hline Parton & St. Louis, US & 1933 & Human & AF205509 \\
\hline Fort Washington & Maryland, US & 1977 & Culexpipiens & AF205504 \\
\hline FL79-411 & Florida, US & 1979 & Culex nigripalpus & AF205467 \\
\hline $69 \mathrm{M}-1143$ & Florida, US & 1969 & Procyon lotor & AF205460 \\
\hline TBH-28 & Florida, US & 1962 & Human & AF205469 \\
\hline GHA-3 & Florida, US & 1962 & Human & AF205505 \\
\hline $72 \mathrm{~V}-4749$ & Colorado, US & 1972 & Culex tarsalis & AF205497 \\
\hline Coav 750 & California, US & 1998 & Culex tarsalis & AF205456 \\
\hline CHLV 374 & California, US & 1991 & Culex tarsalis & AF205464 \\
\hline Imp 1311 & California, US & 1991 & Culex tarsalis & AF205461 \\
\hline Kern 217 & California, US & 1989 & Culex tarsalis & AF205465 \\
\hline SOUE 135 & California, US & 1985 & Culex stigmatosoma & AF205458 \\
\hline IV-824 & California, US & 1978 & Culex tarsalis & AF205457 \\
\hline E22924 & California, US & 1970 & Culex tarsalis & AF205453 \\
\hline BFS-4772 & California, US & 1963 & Culex tarsalis & AF205454 \\
\hline BFS-1750 & California, US & 1953 & Culex tarsalis & AF205455 \\
\hline $65 \mathrm{~V}-310$ & Mexico & 1965 & Butorides virescens & AF205470 \\
\hline $\operatorname{Tr} 9464$ & Trinidad & 1955 & Psorophora ferox & AF205486 \\
\hline GML 903797 & Panama & 1983 & Sentinel chicken & AF205487 \\
\hline GML 902612 & Panama & 1973 & Haemagogus equinus & AF205475 \\
\hline PanAr 902745 & Panama & 1973 & Haemagogus lucifer & AF205476 \\
\hline PanAn 902604 & Panama & 1973 & Cormorant & AF205471 \\
\hline GML 900968 & Panama & Unknown & Unknown & AF205488 \\
\hline 75D-90 & Peru & 1975 & Mosquito sp. & AF205479 \\
\hline SpAn 9398 & São Paulo, Brazil & 1968 & Akodon sp. & AF205472 \\
\hline BeAr 242587 & Belém, Brazil & 1973 & Culex declarator & AF205478 \\
\hline BeAn 246407 & Belém, Brazil & 1973 & Hylophylax poecilonota & AF205482 \\
\hline BeAn 248398 & Belém, Brazil & Unknown & Unknown & AF205480 \\
\hline BeH 203235 & Belém, Brazil & 1971 & Human & AF205484 \\
\hline BeAn 246262 & Belém, Brazil & 1972 & Didelphis marsupialis & AF205483 \\
\hline $79 \mathrm{~V}-2533$ & Santa Fé, Argentina & 1979 & Culex sp. & AF205490 \\
\hline $78 V-6507$ & Santa Fé, Argentina & 1978 & Culex pipiens & AF205481 \\
\hline CorAn 9275 & Cordoba, Argentina & 1967 & Mus musculus & AF205474 \\
\hline CorAn 9124 & Cordoba, Argentina & 1966 & Calomys musculinus & AF205473 \\
\hline SPH 253175 & São Paulo, Brazil & 2004 & Human & $\mathrm{DQ} 022950^{a}$ \\
\hline
\end{tabular}

$a$ : this study 
CA, US), according to the manufacturer's instructions. Primers designed to amplify the complete E gene sequence, described by Kramer and Chandler (2001), were used in RT-PCR and sequencing reactions. RT-PCR was performed with the SuperScript ${ }^{\mathrm{TM}}$ One-Step RT-PCR with Platinium ${ }^{\mathrm{R}}$ Taq System (Invitrogen/Life Technologies, CA, US) in the presence of $4 \mu \mathrm{l}$ of viral RNA and 10 picoMol of each primer. RT-PCR products were directly sequenced using the "ABI Prism ${ }^{\mathrm{R}}$ Big Dye ${ }^{\mathrm{M}}$ Terminator Cycle Sequencing Ready Reaction Kit" (PE Applied Biosystems, Foster City, CA, US), according to the manufacturer's protocol. Sequences were determined in $377 \mathrm{ABI}$ sequencer (PE Applied Biosystems). The E gene sequence of SPH 253157 is deposited in GenBank Data Libraries under accession number DQ022950.

Phylogenetic analysis - Sequence alignment was performed using the multiple sequence alignment method implemented in CLUSTALX (Thompson et al. 1997). Accuracy of nucleotide sequence alignment was examined using amino acid sequence alignment. Maximum likelihood (ML) analyses were performed using PAUP 4.0b10 (Swofford 2003). The best model in PAUP was chosen using ModelTest 3.06 (Posada \& Crandall 1998). This program uses both a hierarchical Likelihood Ratio Test (hLRT) and the AIC (Akaike Information Criterion) to choose among available models; when the hLRT and AIC disagreed the simpler model was chosen. Maximum likelihood searches started with a neighbor-joining tree, on which we then optimized parameters and fixed the values for those parameters for branch swapping on that tree. For each bootstrapped data set PAUP did TBR branchswapping, and only one tree was saved in each replicate (multrees $=$ no). Support for each clade generated for unpartitioned data sets was assessed by 1000 bootstrap replicates using PAUP. For Bayesian analysis, we used the program MrBayes (Huelsenbeck \& Ronquist 2001). Since the kinds of models available in this program have limited overlap with those in PAUP*, Bayesian analysis was carried out using GTR plus site-specific model. Program default values for prior probabilities were used. The Markov Chain Monte Carlo (MCMC) was 1,000,000 generations long, sampling every 100 generations, for a total of 10,001 samples. Of these, the first 1000 were discarded as burn-in, which is well past the point where the likelihood plot reached a plateau.

Evidence for recombination events - Recombination exploratory tests were performed using the SimPlot pro- gram, version 2.5 (Lole et al. 1999). Bootscanning analysis (Salminen et al. 1995) was used to evaluate genetic relatedness between the query sequence and a panel consisting of 39 sequences from SLEV lineages used in the study. A sliding window of $400 \mathrm{bp}$ was moved across the alignment in $20 \mathrm{bp}$ steps, with gap strip on. The genetic distance among sequences in each window, based on neighbor-joining method under Kimura 2-Parameters model was estimated using 100 bootstrap replicates.

\section{RESULTS}

Nucleotide and amino acid sequences analyses Comparison of the nucleotide and amino acid E sequences determined for the strain SPH 253157 with those from representative SLEV American isolates showed a high level of identity. The paired identity ranged from 89.4 to $100 \%$ (nucleotide) and 97.4 to $100 \%$ (amino acid) (MEGALIGN, DNASTAR, Inc.). The strain with the highest percent of nucleotide similarity in relation to SPH 253157 was $79 \mathrm{~V}$ 2533, an Argentinean isolate recovered in 1979 from Culex sp. mosquitoes.

Phylogenetic analysis - Considering both the ingroup and outgroups, the alignment of the E gene sequences generated 1503 sites. The number of constant and variable sites when the outgroups were both included and excluded are in Table II. Alignments are available on request.

A primary objective of this study was to characterize the lineage of the strain SPH 253175 and consequently to test how many phylogenetic lineages exist whitin the group (SLEV). Since the outgroup was quite divergent we suspected that it might cause us to choose inappropriate models or be responsible for long branch effects. To test this, all the analyses were conducted with and without the outgroups.

Phylogenetic analysis with the outgroups excluded ML (Fig. 1) and Bayesian (not shown) topologies were generally the same. They recovered all 40 sequences included in data set into seven phylogenetic lineages, generally according to their geographic origin. These lineages are similar to those identified by Kramer and Chandler (2001). ML analyses were carried under the TrNef $+\mathrm{G}$ model suggested by ModelTest. The ML topology is shown in Fig. 1. SPH 253175 sequence clustered together with 79V-2533 strain of lineage III of Kramer and Chandler (2001). Bootstrap support for the split leading to lineage III is $99 \%$. This lineage is clustered in a major, weakly

TABLE II

Number of constant and variable sites when the outgroups were excluded and included in the data set

\begin{tabular}{|c|c|c|c|c|c|c|c|c|}
\hline \multirow{3}{*}{ Position } & \multicolumn{4}{|c|}{ Without outgroup } & \multicolumn{4}{|c|}{ With outgroup } \\
\hline & \multicolumn{2}{|c|}{ Constant } & \multicolumn{2}{|c|}{ Variable } & \multicolumn{2}{|c|}{ Constant } & \multicolumn{2}{|c|}{ Variable } \\
\hline & $\mathrm{n}$ & $\%$ & $\mathrm{n}$ & $\%$ & $\mathrm{n}$ & $\%$ & $\mathrm{n}$ & $\%$ \\
\hline Position 1 & 433 & 41.2 & 68 & 15.1 & 286 & 42.1 & 215 & 26.1 \\
\hline Position 2 & 480 & 45.6 & 21 & 4.6 & 368 & 54.1 & 133 & 16.2 \\
\hline Position 3 & 139 & 13.2 & 362 & 80.3 & 26 & 3.8 & 475 & 57.7 \\
\hline Total & 1052 & 100 & 451 & 100 & 680 & 100 & 823 & 100 \\
\hline
\end{tabular}


supported group consisting of lineages I and II (Table III). ML bootstrap support for separate groups was generally moderate to strong, however the split leading to lineages IV and VI is weakly supported $(\geq 50 \%)$ and the branch separating the entire lineage I from lineage II is moderately supported (85\%) (Table III). Bayesian 50\% majority rule consensus tree (not shown) is similar to ML topology generated under TrNef $+\mathrm{G}$ model. Posterior probabilities for relationships among SLEV lineages are generally higher than ML bootstrap values (Table III).

Phylogenetic analysis with the outgroups included For the ML analysis, ModelTest suggested the TrNef + G model, the same model suggested when the outgroups
TABLE III

Maximum likelihood (ML) bootstrap and Bayesian supports for St. Louis encephalitis virus lineages I-VII

\begin{tabular}{lcccr}
\hline & \multicolumn{2}{c}{ Without outgroup } & \multicolumn{2}{c}{ With outgroup } \\
\cline { 2 - 5 } Lineage & ML & PP & ML & PP \\
\hline I & 100 & 100 & 97 & 100 \\
II & 100 & 100 & $\leq 50$ & 93 \\
III & 100 & 100 & 99 & 99 \\
IV & 100 & 100 & 100 & 100 \\
V & 100 & 100 & 62 & - \\
VI & - & - & - & - \\
VII & 100 & 100 & 100 & 100 \\
\hline
\end{tabular}

PP: posterior probability

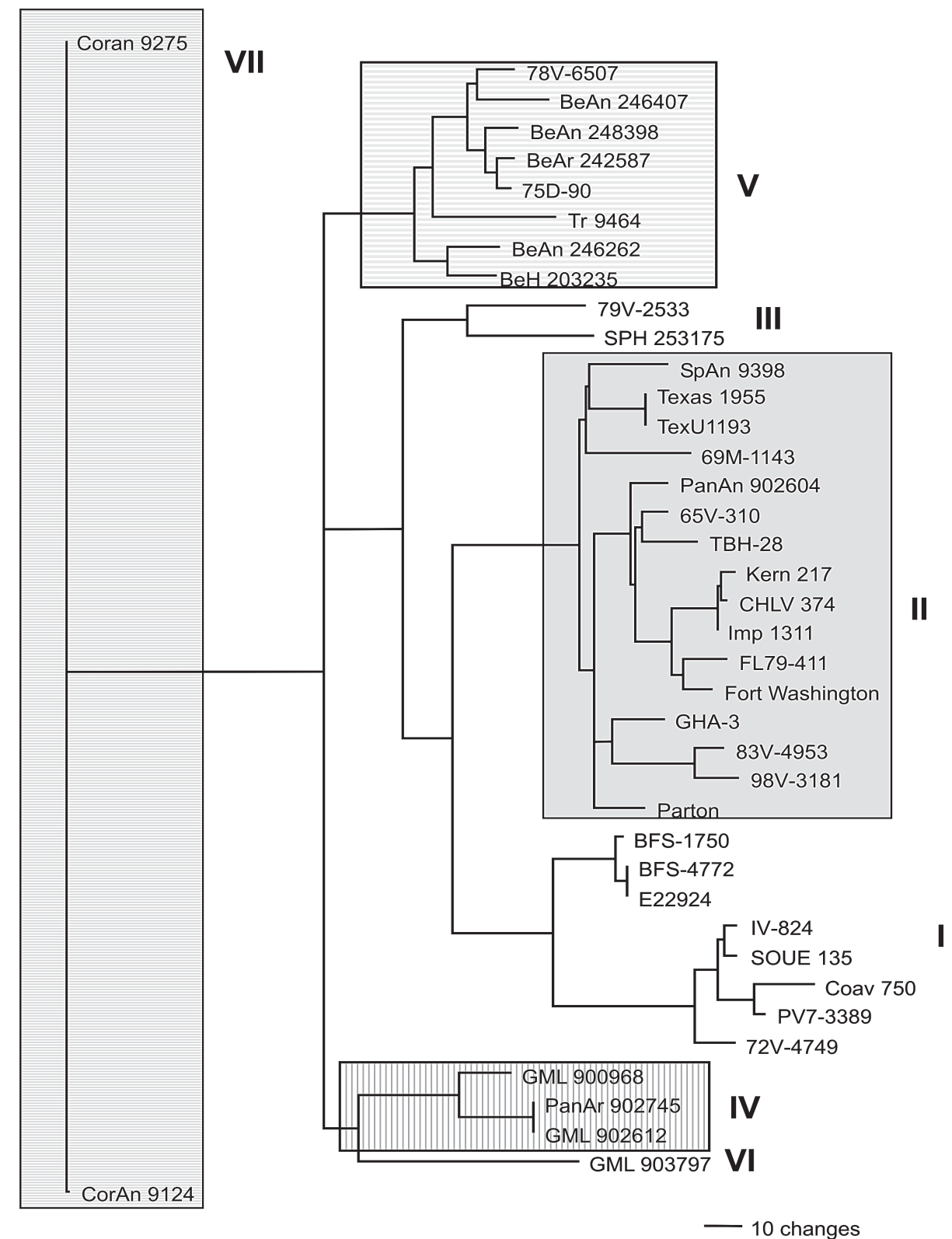

Fig. 1: the single tree identified by maximum likelihood analysis of 40 envelope sequences of St. Louis encephalitis virus data under the TrNef $+\mathrm{G}$ model of nucleotide substitution. Outgroups were excluded from the analysis. The lineages are labeled according to the scheme of Kramer and Chandler (2001). Log likelihood of - 6809.61103. 
were excluded. The position of the root has $99 \%$ bootstrap support. However, maximum likelihood support for the splits leading to lineages II and V is weak (Fig. 2). For the Bayesian analysis, a site-specific model was used. The settings were as described above for the data without the outgroups. The support for relationships among the sequences of each ingroup lineage was generally lower when the outgroups were included in both ML and Bayesian analyses than when the outgroups were excluded (Table III).

Evidence for recombination events - A search for recombination events, in the strain SPH 253157 was performed by bootscanning analysis (Salminen et al. 1995) over the E sequence. The results failed to reveal any recombinant segments in that genome region (results not shown).

\section{DISCUSSION}

All our results revealed that the strain SPH 253157 recovered from a human patient in the 2004 summer is distinct from all six previously characterized Brazilian SLEV. It clusters in lineage III of Kramer and Chandler (2001), which includes Argentinean 79V-2533 strain. Other Brazilian strains isolated from distinct hosts from 1968 until 1973 grouped with other South American and Trinidad samples in lineage V. One Brazilian strain isolated from Akodon sp. clustered with several US isolates in lineage

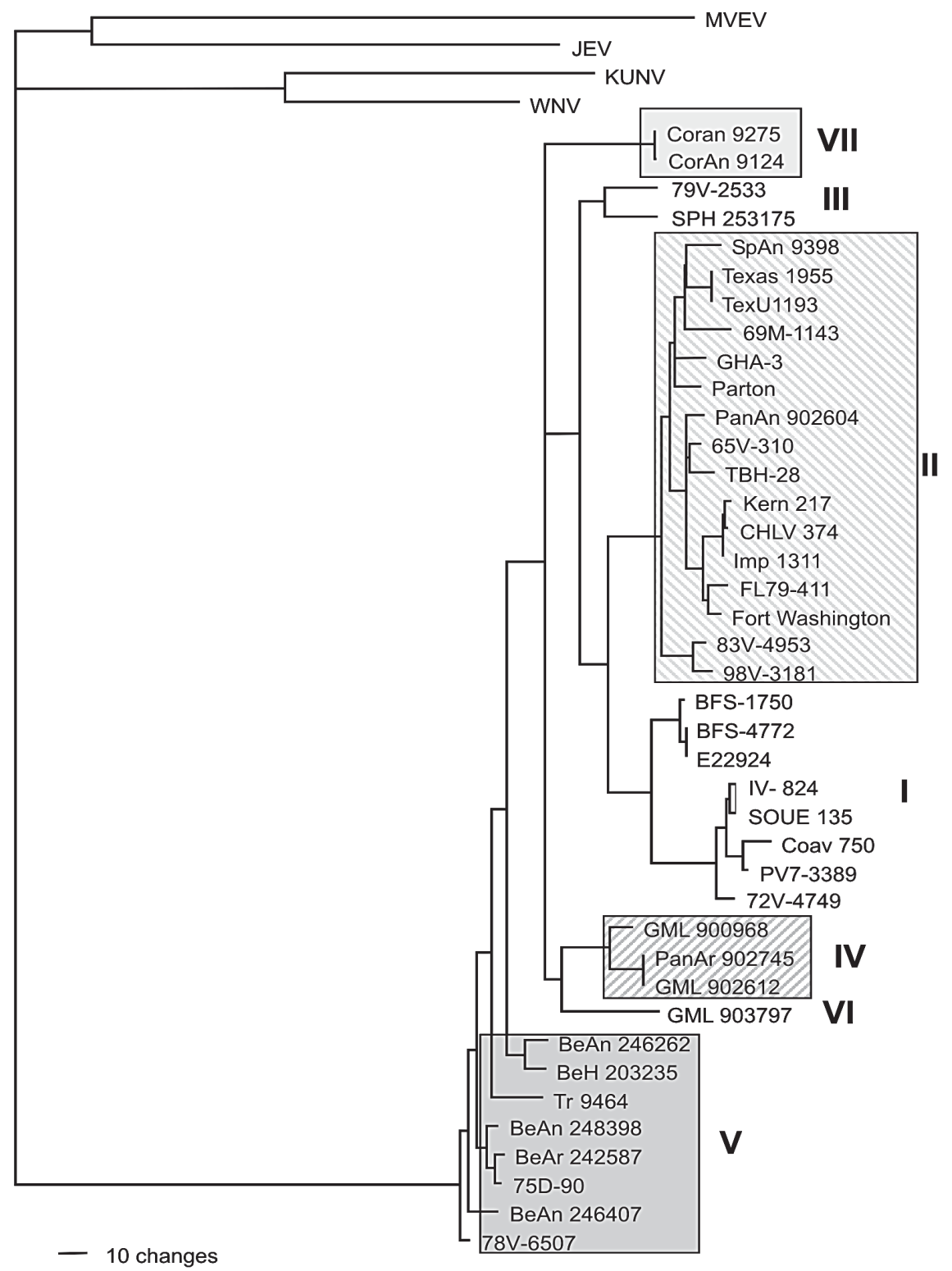

Fig. 2: the single tree identified by maximum likelihood analysis of 40 envelope sequences of St. Louis encephalitis virus data under the TrNef $+\mathrm{G}$ model of nucleotide substitution. Outgroups were included in the analysis. The lineages are labeled according to the scheme of Kramer and Chandler (2001). Log likelihood of - 11452.76425. 
II. Consequently, three distinct lineages of SLEV have been reported in Brazil, suggesting that the virus is circulating and dispersing throughout the Americas. This hypothesis is supported by a recent finding of Twiddy and Holmes (2003) who demonstrated strain GMO94, isolated in Guatemala, to be a recombinant of South (CorAn 9124, Cordoba, Argentina) and North (TNM-711K, Tennessee, US) American strains.

Results of the present phylogenetic analyses corroborate Kramer and Chandler's (2001) hypothesis that the lineages of SLEV virus, which are circulating in the Americas, belong to distinct lineages, and that exists a geographic specificity. Consequently the dynamics of SLEV transmission may be distinct, with the involvement of distinct vectors and virus reservoirs. Results of studies carried out in the Brazilian Amazon region found Culex declarator and Culex coronator to be infected with SLEV. Additionally, members of the families Formicariidae (Formicarius analis, Conopophaga aurita, Thamnomanes caesius and Hylophylax poecilonota), Pipiridae (Chiroxiphia pareola) and Columbidae (Geotrygon montana) were sources of viral isolates and could be involved in the maintenance of the SLEV cycle in that region. Furthermore, monkeys, armadillos, and marsupials may be vertebrate amplifying hosts (Vasconcelos et al. 1998). Regarding to the dynamics of the transmission of SPH 253157 strain isolated in São Paulo, it remains unclear because no virus was isolated either from birds or mosquitoes during the eco-epidemiological studies carried out in that region where the patient was probably infected (Rocco et al. 2005).

It is important to emphasize that infection caused by SLE virus, as well as several arboviruses that affect the central nervous system, presents diverse symptoms that are hardly diagnosed unless in cases of epidemics. Few physicians suspect initially of the disease even in endemic areas (Reisen 2003). In the present human case of SLEV infection, it was first suspected as a dengue case. The following epidemiological investigation included clinical and laboratorial studies which led to the successfully identification of SLEV as the etiological agent. The lack of systematic epidemiological surveillance activities toward arboviruses of minor importance compared to Yellow fever, Dengue fever, and Rocio encephalitis, for instance, may partially explain the few number of clinical cases of Saint Louis encephalitis reported both in Brazil and tropical America. Others factors including the attenuation of viral strains that was observed in rodent strains isolated in São Paulo and Argentina (Monath et al. 1980) and the early acquisition and accumulation of human immunity, revealed among residents in the Amazon region (Pinheiro et al. 1986, Vasconcelos et al. 1998) and in different areas of the state of São Paulo (Iversson et al. 1981, Romano-Lieber \& Iversson 2000) as well as in several Argentina counties (Sabattini et al. 1998) may be also considered.

Finally, a particular concern is relative to WNV, another member of the Japanese encephalitis group, which transmission cycle involves wild birds and Culex mosquitoes. WNV caused an outbreak of encephalitis in New York in 1999 and SLEV was initially suspect to be the etiological agent (Briese et al. 1999, Campbell et al. 2002). Lillibridge et al. (2004) reported that in Harris County, Texas, an endemic region for SLEV, WNV appeared and spread rapidly throughout the area. Surveillance data indicated that SLEV and WNV can coexist, despite their ecologic, antigenic and genetic similarities and both viruses will probably persist in Harris County. Consequently, it is important to emphasize the necessity of robust surveillance program for arboviruses, which are generally weak or even inexistent in several countries (Gubler 2002). Furthermore, to reduce the risk of epidemics, health professionals, especially in cases of hardly recognized viral infections, should carry out exhaustive clinical, epidemiological and laboratorial investigations. Diagnostics methods as those represented by reverse-transcription amplification techniques, including the recent real time-PCR procedure (Mackay et al. 2002) are specially recommended to ensure rapid identification of the viral agent and allow a prompt surveillance action by health authorities.

\section{ACKNOWLEDGEMENTS}

To Dr Tiyo Sakurai (Instituto Adolfo Lutz, São Paulo, Brazil) and Dr Peter G Foster (Natural History Museum, London, UK) for suggestions and providing helpful comments to improve the paper.

\section{REFERENCES}

Briese T, Jia XY, Huang C, Grady LJ, Lipkin WI 1999. Identification of a Kunjin/West Nile-like flavivirus in brains of patients with New York encephalitis. The Lancet 354: 12611262.

Calisher CH, Karabatsos N, Dalrymple JM, Shope RE, Porterfield JS, Westaway EG, Brandt WE 1989. Antigenic relationship between flavivirus as determined by cross-neutralization tests with policlonal antisera. J Gen Virol 70: 3743.

Campbell GL, Martin AA, Lanciotti RS, Gubler DJ 2002. West Nile virus. The Lancet Infec Dis 2: 519-529.

Castle ET, Nowak T, Leidner U, Wengler G 1985. Sequence analysis of the viral core protein and the membrane-associated proteins VI and NV2 of the flavivirus West Nile virus and of the genome sequence for these proteins. Virology 145: 227-236.

Causey OR, Theiller M 1958. Virus antibody survey on sera of residents of the Amazon Valley in Brazil. Am J Trop Med Hyg 7: 36-41.

Causey OR, Shope RE, Theiller M 1964. Isolation of St. Louis encephalitis virus from arthropds in Pará, Brazil. Am J Trop Med Hyg 13: 449.

Chambers TJ, Hahn CS, Galler R, Rice CM 1990. Flavivirus genome organization, expression, and replication. Ann Rev Microbiol 44: 649-688.

Coia G, Parker MD, Speigh G, Byrne ME, Westaway EG 1988. Nucleotide and complete amino acid sequences of Kunjin virus: definitive gene order and characteristics of the virusspecific proteins. J Gen Virol 69: 1-21.

Dalgarno L, Trent DW, Staruss JH, Rice CM 1986. Partial nucleotide sequence of the Murray Valley encephalitis virus genome. Comparison of the encoded polypeptides with yellow fever virus structural and non-structural 
proteins. J Mol Biol 187: 309-323.

Day JF 2001. Predicting St. Louis encephalitis virus epidemics: Lessons from recent, and not so recent, outbreaks. Ann Rev Entomol 46: 111-138.

Gubler DJ 2002. The global emergence/resurgence of arboviral diseases as public health problems. Arch Med Res 33: 330342 .

Huelsenbeck JP, Ronquist F 2001. MRBAYES: Bayesian inference of phylogeny. Bioinformatics 17: 754-755.

Iversson LB, Travassos da Rosa APA, Travassos da Rosa J 1981. Serological studies in research on arbovirus antibodies in the human population of the Ribeira-Valley region. II - Survey of patients of Pariquera-Açu Regional Hospital. Rev Saúde Pública 15: 587-602.

Kramer DL, Chandler LJ 2001. Phylogenetic analysis of the envelope gene of St. Louis encephalitis virus. Arch Virol 146: 2341-2355.

Lillibridge KM, Parsons R, Randle Y, Travassos da Rosa APA, Guzman H, Siirin M, Wuithiranyagool T, Haidley C, Higgs S, Bala AA, Pascua R, Meyer T, Vanlandingham DL, Tesh RB 2004. The 2002 introduction of West Nile virus into Harris county, Texas, an area historically endemic for St. Louis encephalitis. Am J Trop Med Hyg 70: 676-681.

Lole KS, Bollinger RC, Ramesh SP, Deepak G, Kulkarni SS, Novak NG, Ingersoll R, Sheppard HW, Ray SC 1999. Fulllength human immunodeficiency virus type 1 genomes from subtype C-infected seroconverts in India, with evidence of intersubtype recombination. J Virol 73: 152-160.

Lopes OS, Sachetta LA, Coimbra TL, Pereira LE 1979. Isolation of St. Louis encephalitis virus in south Brazil. Am J Trop Med Hyg 28: 583-585.

Mackey IM, Arden KE, Nitsche, A 2002. Real-time PCR in virology. Nucleic Acids Res 30: 1292-1305.

Monath TP, Heinz FX 1996. Flaviviruses. In BN Fields, DM Knipe, PM Howley (eds.), Fields Virology, 3rd ed., Lippincott, Raven Publishers, Philadelphia, New York, p. $961-1034$.

Monath TP, Tsay TF 1987. St. Louis encephalitis: Lessons from the last decade. Am J Trop Med Hyg 37: 40s-59s.

Monath TP, Cropp CB, Bowen GS, Kemp GE, Mitchell CJ, Gardner JJ 1980. Variation in virulence for mice and rhesus monkeys among St. Louis encephalitis virus strains of different origin: Am J Trop Med Hyg 29: 948-962.

Muckenfuss RS, Armstrong C, Webster LT 1934. Etiology of the 1933 epidemic of encephalitis. JAMA 103: 731-733.

Nitayaphan S, Grant JA, Chang GJ, Trent DW 1990. Nucleotide sequence of the virulent SA-14 strain of Japanese encephalitis virus and its attenuated vaccine derivative, SA-
14-142. Virology 177: 541-552.

Pinheiro FP, LeDuc JW, Travassos da Rosa APA, Leite OF 1981. Isolation of St. Louis encephalitis virus from a patient in Belem, Brazil. Am J Trop Med Hyg 30: 145-148.

Posada D, Crandall KA 1998. Modeltest: testing the model of DNA substitution. Bioinformatics 14: 817-818.

Reisen WK 2003. Epidemiology of St. Louis encephalitis virus. Adv Virus Res 61: 139-183.

Rocco IM, Santos CLS, Bisordi I, Petrella SMCN, Pereira LE, Souza RP, Coimbra TLM, Bessa TAF, Oshiro FM, Lima LBQ, Cerroni MP, Marti AT, Barbosa VM, Katz G, Suzuki A 2005. St. Louis encephalitis: first virus isolation from a human in São Paulo State, Brazil. Rev Inst Med Trop São Paulo 47: 281-285.

Romano-Lieber NS, Iversson LB 2000. Inquérito soroepidemiológico para pesquisa de infecção por arbovirus em moradores de reserva ecológica. Rev Saúde Pub (S.Paulo) 34: 236-242.

Sabattini MS, Avilés G, Monath TP 1998. Historical, epidemiological and ecological aspects of arboviruses in Argentina: Flaviviridae, Bunyaviridae and Rhabdoviridae. In APA Travassos da Rosa, PFC Vasconcelos, JFS Travassos da Rosa (eds), An Overview of Arbovirology in Brazil and Neighboring Countries, Instituto Evandro Chagas, Belém, p. 113-34.

Salminen MO, JK, Carr DS, Burke McCutchan FE 1995. Identification of breakpoints in intergenotypic recombinants of HIV type 1 by bootscanning. AIDS Res Hum Retroviruses 11: $1423-1425$.

Spence LP 1980. St. Louis encephalitis in tropical America. In TP Monath, St. Louis Encephalitis, Am Publ Hlth Assoc, Washington, DC, p. 451-471.

Swofford DL, PAUP*. Phylogenetic Analysis Using Parsimony (*and Other Methods), Version 4. 2003. Sinauer Associates, Sunderland.

Thompson JD, Gibson TJ, Plewniak F, Jeanmougin F, Higgins DG 1997. The CLUSTALX windows interface: flexible strategies for multiple sequence alignment aided by quality tools. Nucleic Acids Res 24: 4876-4882.

Twiddy SS, Holmes EC 2003. The extent of homologous recombination of the genus Flavivirus. J Gen Virol 84: 429440.

Vasconcelos PFC, Travassos da Rosa APA, Pinheiro FP, Shope RE, Travassos da Rosa JFS, Rodrigues SG, Dégallier N, Travassos da Rosa ES 1998. Arboviroses pathogenic for man in Brazil. In APA Travassos da Rosa, PFC Vasconcelos, JFS Travassos da Rosa (eds), An Overview of Arbovirology in Brazil and Neighboring Countries, Instituto Evandro Chagas, Belém, p. 72-99. 